\title{
Управление телесными практиками: от традиции до современности (на примере практиках йоги)
}

\author{
Виктория Лобас \\ Национальный технический университет «Харьковский политехнический институт», Харьков, \\ Украина
}

\begin{abstract}
АННОТАЦИЯ
Автор пытается путем основательного исследования структуры тела, его функционального значения показать возможность управлять им и даже конструировать его. Практики Йоги позволяют по-новому посмотреть на тело человека. Они также способствуют созданию особой когнитивной ситуации вокруг темы управления телом и телесным. Это раскрывает совершенно новые горизонты жизни для определенной части населения и возможность инвестировать знания в процесс конструирования телесного. Знание о теле, которые мы находим в древних текстах и на которые опирается Йога, еще раз подчеркивают особую миссию Йоги. В статье подтверждается идея целостности духовного и телесного, чего Йога никогда не теряла.
\end{abstract}

Ключевые слова: управление телом, Йога, конструирование телесного, тело как конструкт.

\section{ВВЕДЕНИЕ}

Актуальность. Современная культура Запада сформировалась под давлением метафизического дискурса с его онтологическими и эпистемологическими напряжениями, опираясь на жестко действующего субъекта конституционного характера с характерной для него оппозицией - «духовное-телесное». Но современная философия и философия Востока (философии Йоги) пересмотрела и указала на узость такого понимания. На примере Йоги демонстрируется тезис о том, что ее практики и управление ими способствовали сохранению духовного и телесного, сохранению той целостности, которую человек не теряла никогда. Практики Йоги позволяют современной философии обращаться к философии Востока с целью согласовать с альтернативными и, казалось бы, далекими от западных ценностей мировоззренческими идеями восточных культур, размышления вокруг вопроса тела и его управления.

Проблема исследования. Проблема состоит в том, какие знания о теле подчеркивают особую миссию Йоги способствовать сохранению особого понимания управления телесным, в частности, как ступени к духовному росту и как изменяются в контексте традиции и современности.

Цель исследования: на основе анализа телесных практик Йоги, представленных в древних текстах Йоги, выйти на понимание тела как конструктивистской практики, а управление им расценивать как ступеньку к духовному росту человека.

\section{МЕТОДОЛОГИЯ ИССЛЕДОВАНИЯ}

Анализ научной литературы, синтез, обобщение. Научная литература и теоретическая интерпретация с целью обобщения исследований, проведённых по этой теме. Предметом исследования-управлениетеломителеснымипрактиками.Егоонтологическийиантропологический измерения будут способствовать пониманию того, что тело может быть инструментом человекайога на пути восхождения к духовному, а феноменологический и эпистемологический измерения 
подчеркнут конструктивистский характер действия с ним. Будет проведён анализ управления телом и телесными практиками. Его онтологический и антропологический измерения будут способствовать пониманию того, что тело может быть инструментом человека-йога на пути восхождения к духовному, а феноменологический и эпистемологический измерения подчеркнут конструктивистский характер действия с ним.

\section{РЕЗУЛЬТАТЫ ИССЛЕДОВАНИЯ И ДИСКУСИЯ}

Анализ начинается с древнеиндийского текста Аюверды, которая входит в сокровищницу древних достижений мира. Ее главная концепция дает онтологическое и одновременно натурфилософским понимание телесного. Следует разъяснить, что Аюрведа - это текст традиционной индийской медицины. Ее содержание, прежде всего, приспособлено к задачам утилитарного характера. Можно сказать, что это своего рода указания на относительно прагматического характера заботы о человеке, цель которых - сохранить не только здоровье человека, но и управлять телом с целью формирования гармонии между Вселенной и человеком.

Восточные культуры всегда исходили из того, что природный мир, в котором живет человек, это - живой организм, а не обезличенное неорганическое поле, которое можно перепахивать и переделывать. Долгое время Новоевропейская наука относилась к этим идеям как к пережиткам мифа и мистики. Но после развития современных представлений о биосфере как глобальной экосистемы выяснилось, что окружающая среда действительно представляет собой целостный организм, в котором живет человек. Главный тезис аюрведической концепции - тело является продуктом пяти «великих элементов» (махабхут): земля, вода, воздух, огонь и эфир. Но в то же время телесное было представлено стихией только земли. Опорные элементы тела должны быть твердыми, похожими на землю. Итак, земля выступает как формообразующий элемент телесного. Но описание гармоничности телесного в Аюрведе сделано на почве нескольких древних индийских текстов. Иногда каждый из них имел достаточно противоположные утверждения о телесной организации, и это не случайно. Известно, что в Аюрведе слиты в единое целое позиции, которые можно расценить как противоположные. Например, устойчивость тела, с одной стороны, и способность к движениям, с другой, постоянство переменных физиологических процессов и в то же время статичность в системной организации тела. Это вызывает удивление и требует объяснения.

Современный востоковед В. Лысенко (2009) посвятила свои исследования вопросу такого, на первый взгляд, странного сочетания несовместимого. При анализе структуры телесных элементов и эмпирического исследования тела она задала вопрос: как сочетаются данные древних текстов Аюрведы, Санкхья и Вайшешика. На что именно она обращает внимание. В «Махабхарате» говорится, что тело состоит из земли и сохраняется от разрушения благодаря пище, является модификацией земли. Но в Аюрведе по этим ссылкам следует тезис об элементном составе тела: «Симптоматично, что эти слова следуют за утверждением о том, что тело состоит из пяти первоэлементов. Таким образом, екабхаутика (тело состоит из земли) и панчабхаутика (тело состоит из пяти первоэлементов) сосуществуют без всяких видимых неудобств» (Лысенко, 2009). Н. Лысенко (2009) ставит вопрос о понимании причинных связей при описании структуры 
телесного в общем плане, а также при описании болезней. По ее мнению, именно идеи таких разных по содержанию текстов, Санкхья и Вайшешика, дают ответы на эти вопросы. Общие идеи текстов, их понятийный и терминологический инструментарий помогают создать целостное представление о человеческом теле как системе в ее статике и динамике: «если Вайшешика преуспела в понимании статической структуры тела, то Санкхья была более сильна в исследовании тела как психосоматического процесса» (Лысенко, 2009).

Разъяснения такого сложного синтеза и понимания работы целостной системы возможно при условии сочетания этих противоположных по идеям текстов. Мы предлагаем цитаты, которые дают понимание и значение психосоматической системы любого индивида (ибо речь идет не только о йоге), указывая на причинно-следственные связи человека и окружающего мира. «Эволюция пракрити является постепенным, непрерывным преобразованием элементов друг в друга: с акаши возникает ветер, из ветра - огонь, из огня - вода, из воды - земля. Согласно Ишваракришне, эти грубые элементы эволюционируют из соответствующих танматры - тонких элементов (чувственных способностей). Самая распространенная схема эволюции, названная исследователями «теорией аккумуляции», заключается в том, что каждый следующий элемент добавляет к своим свойств свойства предыдущего: танматры звука производит акашу, танматры звука плюс танматры соприкосновения - ветер, танматры звука и прикосновения плюс танматры зрения - огонь, предыдущие танматры плюс танматры вкуса - воду, все предыдущие плюс танматры запаха - землю» (Лысенко, 2009). «В Вайшешика, наоборот, первоэлементы суть генетически и онтологически независимые субстанции (дравьа), а не различные преходящие состояния некой единой сущности.

Если мы подчеркиваем онтологический характер обустройства телесного, то нам необходимо также показать необычный характер восприятии земли на ментальном уровне древних индейцев. По данным J. Mooney (1896), который делал свои полевые заметки на рубеже XIX и $\mathrm{XX}$ веков, один из индийских проповедников категорически отказывался обрабатывать землю, воспринимая ее и процесс ее обработки как насильственное вмешательство в космическую (то есть сотериологических) обустройство Вселенной. Вот слова, которые свидетельствуют об онтологии тела на уровне восприятия онтологии Вселенной: «Вы требуете от меня, чтобы я обрабатывал землю? Но могу ли я взять нож и вонзить его в брюхо своей матери? Ведь если я так сделаю, она никогда не примет в себя снова мое мертвое тело. Вы требуете от меня, чтобы я разрыхлял почву и вытаскивал камни? Но могу я исказить тело матери, добираясь до самых костей? Ведь если я так сделаю, я больше не смогу войти в него, чтобы возродиться вновь» (Mooney, 1896). Странным образом проповедник сравнивает свое тело и тело земле, подчеркивая онтологическое соединение. Эти слова уходят корнями в глубокую древность, но свежесть восприятия позволяет почувствовать глубину понимания и восприятия земли (и в смысле элемента Вселенной, и в смысле земли-матери, дающей жизнь, и в смысле единения с родной Землей и т.д.).

Спасительный (сотереологичний) характер поверхности земного шара, недр земли мы находим во многих мифах и легендах, сказках и балладах, который подчеркивает наличие радости, как в истории появления нового человека на земле, так и в радости соединения с ней в случае захоронения. Если же обращать внимание на мифы и ритуалы, то в них приглашаются 
возникновения какой-то новой космической ситуации, то есть это всегда рассказ о чем-то создано, о том, что какая-то вещь произошла, то есть описывается начало существования. «Он (миф) повествует лишь о реальном мире, о том, что реально произошло, что в полной мере проявилось» (Элиаде, 1994). Именно поэтому отношение к земле и все действия с ней приравниваются к священным действий, а работа на земле приравнивалась к подготовке возможного «выхода»к вселенскому, к миру Духа.

Можно утверждать, что в тексте Аюрведы древние ценности получили новые контексты и интерпретации. Именно с помощью «космического» понимание элементного состава тела становится понятной именно такая онтологическая сложность человеческого тела. Подчеркивается, что в любой действенной ситуации, в которой телом надо управлять при выполнение любых функций, человек «космизуется» - воспроизводит в своем человеческом масштабе систему взаимно обусловленных факторов и ритмов, которые и составляют мир, Вселенную в целом. Этим подчеркивается сотереологический характер состава и содержания телесного.

Есть тексты Йоги, где присутствует описание тела и его возможности как задачи управления им. Одна из наиболее впечатляющей по своей глубине книга - это Йога-Сутра Патаджали. Ее автор М, Патаджали (1998) - йог, врач, философ - систематизировал формы и методики практических занятий. Именно здесь речь идет о теле человека-йога и о конструировании телесного как общее-космической задачи каждого, кто встал на стезю своего самосовершенствования. Если сравнить переводы этой книги, то сам процесс сравнения способствует формированию особого нарратива первоисточника. В переводах Е. П. Островской и В. И. Рыжего главы имеют следующие названия: первая - «О сосредоточенности»; вторая - «О способах осуществления (йоги)»; третья - «О совершенных способностях»; четвертая - «Об абсолютном освобождении». В переводах А. Фалькова названия более или менее перекликаются: первая - «Основы работы духа»; вторая «Практическая реализация»; третья - «Силы»; четвертая - «Освобождение». Но в переводах К. Свенссона перед нами разворачивается более масштабное понимание сутр (в качестве управления не столько телесным, сколько трансцендентным характером знаний): первая - «Самадхипада, или о созерцании»; вторая - «Садханапада, или о духовном ученичестве»; третья - «Вибхутипада, или о совершенных способностях»; четвертая - «Кайвальяпада, или об освобождении» (Патанджали, 1998).

Об управлении телесным хорошо представлено в текстах М. Патанджали (1998). Он пишет об аскетизме (тапасья), умственном самопостижении (свадхьяя) и служении богу (Ишварапронидхана), то есть речь идет о трех видах действия Йоги. В сутре 30 (Знание тела) даются названия основных частей тела: пупок и центр, но рядом с ними стоят такие слова, как организация и знания: (Nabhi - пупок; Chakre - центр; kaya - тело; vуuha - организация; jnanam - знание) (Патанджали, 2006). Затем уже идет разъяснение, почему в центре внимания оказывается пупок (с его помощью и именно на нем йог достигает знаний), от него идут потоки в другие части тела. Постижение же сознания идет на Сердце.

Bозникает вопрос: зачем йогу знать феноменологические особенности тела? Создается впечатление, что оно является не только антенной для связи с Космосом, но и энергетической структурой, материальной формой реализации сознания, носителем откровения Абсолюта и тому 
подобное. То есть управление телом - процесс не только сложный, но и опасный. Действительно, действия йога направлены именно на выход за пределы человеческого, земного. Практикой самьяму понимается природа Пуруши. Чтобы понять Пурушу, йог должен идти за пределы царства пракрити. Это субъектное осознание или осознание самости, которое появляется после выхода за пределы пракрити (Сутра 36. Знание пуруши) (Сарасвати, 2006). Тело как жертвенник, или как его основная составляющая имеет не только состояние, состав и тому подобное. Речь идет о задачах «космического» характера: структурировать себя, сконструировать такое тело, которое соответствовало бы требованиям и ритуального (мистического), и онтологического (метафизического). Итак, тело не просто реализует какие-то функции, его фактом подчеркивается космическое предназначение человека за счет конструирования телесных навыков, умелой настройки работы сердца, мозга, частей тела со всеми вытекающими последствиями. Без обращения к феноменологии телесного в древних текстах такой процесс невозможен.

В главе 33 (Духовное видение) описываются условия и последствия духовного видения с постоянным обращением к теме телесного (Murdhajyotiși siddhadarshanam Murdha - корона головы; jyotiși - к свету; siddha - умелый; darshanam - духовное видение) (Сарасвати, 2006). Путем выполнения самьяму на свете короны над головой (сахасраре) достигается духовное видение мастеров йоги. Мурдха здесь означает сахасрару. Свет скорее связано с аджна чакрой, которая находится в центре между бровями. Самьяму на аджна чакре может привести к результату быстрее. «Когда перед разумом вспыхивает этот мир, это дает начало духовному видению. Мастера могут жить без тела, так как они получили полный контроль над своими осознанными и не осознанными ментальными и психическими функциями, поэтому они могут отделить себя от тела. Их называют сиддхами, потому что они могут жить без физического тела. Обычно их можно видеть, потому что физическое тело отсутствует. Но, когда наблюдается самьяму на аджна чакры или сахасрара чакры, йог может встретиться с ними и общаться, и таким образом получить от них руководство и вдохновение» (Йога-сутра Патанджали, 2001).

Есть тело грубое и тонкое. В случае необходимости, сознание может захватить чужое тело при полном расслаблении: зная точки входа и выхода, разрыв с телом вполне осуществимый. Описания сложных манипуляций с телом человека поражают: речь идет о переходе в тела других людей в условиях обладания особыми знаниями (сутра 39). Тело можно сделать маленьким, большим, тяжелым и т.д., и наконец - совершенным. По мнению Патанджали, «совершенство физического тела включает красоту, грацию, энергию и прочность. Следует помнить, что грация (уродливая она или хорошая) не зависит от комплекции» (сутра 47) (Сарасвати, 2006). Следовательно, организация управления телесным сопровождается в жизни йога обязательным пониманием сложной архитектоники тела, потому что знания дают возможность осознавать физическое с целью его постоянной трансформации. Практики Йоги дают возможность совершенствовать и делать тонкими слух, осязание, зрение, вкус и обоняние, можно получить сверхъестественный слух и тому подобное. Это приносит изящество, совершенство тела, незыблемость его свойств.

Принципом, который дает возможность понять возможности этой архитектонической развития, является Пуруша и Читта. «Пуруша (purușa) - чистое сознание» (Сарасвати, 2006). Но именно в текстах Йоги мы можем осознать сложность и значение такого на первый взгляд 
понятного принципа. в 90-х годах XX века современная женщина-йогиня (европейского происхождения), которая жила и занималась Йогой достаточно долгое время в Индии, откровенно писала, что европейцы, которые занимаются Йогой, потеряли или совсем не занимались такой сложной и содержательной составляющей Йоги, как Читта (в переводе с санскрита: сознание, разум, мышление, чувства). «Читта (chitta) - универсальная сознание, включая сознательный, подсознательный и бессознательный уровне ума» (Сарасвати, 2006). Это материя мысли, сознание, разум, которым необходимо управлять. «Читта - это зеркало, с помощью которого мы воспринимаем мир, получая ощущение от наших органов. Здесь - наши впечатления, предназначенные для дальнейшего использования (обдумывание). Читтой также называют субстанцию, связанную с памятью и привычками, или органом мышления, элементом внутреннего инструмента, ниже умом, интеллектом. В буддийской теории дхарм Читта - это дхарма сознания» (Йога-сутра Патанджали, 2001).

В тексте «Йога-сутра Патанджали» дается знакомство с субъектным и объектным опытом, с пониманием и практикой Читта и Пуруши, и подчеркивается, что Читта и Пуруша принципиально разные. Осознание их неразличение существует или как субъектный, или как объектный опыт (Сарасвати, 2006). Патаджали уделяет внимание вопросу познания соотношение сознания и тела. После объяснения трех мощных сил (Дхарана - сосредоточенность на предмете; Дхиана - состояние, благодаря которому мнение сосредотачивается на предмете, или в теле, или вне тела и удерживается в этом положении; самадхи - сосредоточенность на предмете и восприятии только внутреннего впечатление, смысла) он указывает, что «эти три составляющие составляют Самаияму» (Философия Йога, 1992). Достигнув ее, йог находит свет знания. При умении делать Самаияму все силы подчиняются йогу, и он может с помощью этого оружия познавать и осуществлять различные функциональные вещи с предметами. Сосредоточенность сознания достигается сложными упражнениями, а свидетельством «вхождения» в такое состояние становится «преобразованием формы, времени и состояния в тонкую или грубую материю и в органы чувств» (Философия Йога, 1992).

Сила Самаиямы способствует манипулированию элементами (грубыми и тонкими), что позволяет Патаджали совершать различного рода манипуляции с телесным. Эта установка приобретает характер константы конструктивного характера, а именно: йог может себя сделать огромным, легким, тяжелым и т. Д. Более того именно тело йога становится несокрушимым, потому что он получает власть над всеми элементами и может подчинять их себе. К этому состоянию добавляется сила космического характера - игра со временем «ломая жезл времени, он живет в этой вселенной со своим телом» (Философия Йога, 1992). А такой человек уже выходит в другие (отличные от земных) онтологии и для него уже не существуют болезни, страдания и даже смерть. Механизмом такого процесса становится процесс Самаиямы. Нам желательно было подчеркнуть особую эпистемологические параллельность сознания и тела в этой ситуации, а именно - «как в результате овладения элементами получается просветление тела, так через подчинение сознания происходит просветление сознания» (Философия Йога, 1992).

Мы читаем в древних текстах «инструкции» по преодолению и конструирование фундаментального мистического опыта, то есть преодоление человеческого состояния. Оно 
выражается различными способами, но всегда центральной точкой остается человеческое тело: полеты в небеса, переход в другое тело, размышления над траекториями движения души и тому подобное. Ученые / философы дают объяснения таким фактам в виде мистического опыта и метафизического понимания подобных рекомендаций / уроков. В первом случае, когда речь идет о вознесении души через точку в голове, имеют в виду особое состояние (экстаз, транс, сопровождающие изменение сознания). Во втором (метафизично) - о несчастье привычного (обычного) мира проживания. И в первом, и во втором случае происходит разрыв или преодоления онтологического состояния, уровня, при котором способ существования, способ восприятия меняется «от обусловленного существования в необусловленного, то есть к полной свободе» (Элиаде, 1994).

Современная культура, отталкиваясь от нового понимания тела и опираясь на выработку путей конструирования тела в новых условиях его развития, ставит ударения на конструировании телесного, и не случайно. Современная культура меняет отношение к телу и чувствует одиночество сознания: «Если в метафизической традиции отношения были поставлены исключительно в зависимость от процессов человеческого сознания, а постмодернистская традиция обнажила, поставила в центр внимания такое положение, то культура присутствии поставила ударение на разрыве с картезианско-метафизической традицией» (Dolska, Gorodiskaya, Tararoyev, 2019). Видимо не случайно Йога стала тем феноменом, где внимание к телу, к культуре тела, еды, стиля жизни получили широкого масштаба. Хотя надо быть откровенными: «По последним данным статистики и аналитики популярность Йоги падает: специалисты считают, скорее всего, йогой не слишком интересуется молодое поколение, но при приближении к возрасту 30-35 лет активность тех, кто хочет заниматься ею с целью улучшения здоровья «я, увеличивается» (Lobas, 2020).

В современной культуре потребления отношение к работе с физическим телом имеет другой ракурс, чем в восточной традиции. Это не означает, что человек перестает заниматься идеей восхождения к высокому за счет работы с телом, но ударения существенно измениться. Сегодня Йога с ее активным использованием телесного, прежде всего, работой с органами моторного характера, приобрела широкомасштабного применения в любых формах и практиках. Надо подчеркнуть, что есть также практические указания в виде учебной литературы, в которой физические занятия Йогой пересекаются с медитативными практиками, выходом из медитаций, освоением стрессового напряжения и тому подобное. Есть программа, которая известна как Mindfulness-Based Stress Reduction, сокращенно MBSR. Ее можно перевести как Уменьшение стресса на основе внимательности. Уже существуют учебники и пособия, в которых разъясняют особенности применения этой программы. Примером может стать пособие последних лет выпуска Mindfulness-Based Stress Reduction (MBSR) - Authorized Curriculum Guide. Version Revised and Editedby, среди авторов которого «основатель программы MBSR и создатель учебной программы MBSR» Jon Kabat-Zinn (Santorelli, et., 2017).

Такие программы начинают использоваться в учреждениях социально-медицинского направления. Все чаще медицина опирается на сравнительный анализ работы человека в контексте осознания на базе когнитивно-поведенческой терапии или обычной терапии (даже тогда, когда речь идет об обычном болевой синдром в органах функционального характера). Делается много 
клинических исследований по вопросам снижения стресса, а каждые испытания проводятся в соответствии с протоколами, дается домашнее задание. Работу ведут несколько инструкторов с опытом работы именно по программе MBSR, или активизируется работа курсов при Медицинских школах, в которых проводятся встречи-тренинги с лицензированными психологами и тому подобное. Занятия, как правило включают в себя дидактические содержания и практику осознания (сканирование тела, йога, медитация, внимание к мыслям, эмоций и ощущений, сидячая медитация с осознанием дыхания и медитация при ходьбе). Как правило, выводы делаются положительные, эффекты лечения по сравнению с пост-лечением контрастируют, эффект положительный характер носит долговременный характер, а «лечения разума и тела, такое как MBSR и CBT, может обеспечить пациентам длительный эффект» (Cherkin, et., 2016).

Практики Йоги приобретают новое звучание (они изменились, трансформировались под вызовами и напряжениями, которые несет собой современное общество), а сама Йога превратилась в новый глобальный проект с новыми целями. Несмотря на то, что для представителя современной культуры тело утратило свою «открытость» к Миру и связь с Космосом, Йога предлагает вернуться к человеческой телесности в условиях реализации основной цели - приближения к духовному росту. Поиски духовного остаются как главные в управлении йога с телом: оно остается ступенью к духовному и в то же время духовно значимым, поскольку способно к проницаемости, является мобильным и готовым для метафизических и онтологических трансформаций.

\section{ВЫВОДЫ}

По данным древних текстов, размышления человека отталкивались от отправной точки человеческого индивида, от его психосоматической системы. Практика Йоги внесла элемент управления телесным в культуру Запада как компонент духовной, социальной и физической жизни, он стал одним из многочисленных ответов на вызовы кризиса культуры Запада. Осознание таких измерений тела, как сотереологический, онтологический, эпистемологический и феноменологический способствуют созданию особой когнитивной ситуации вокруг темы управления телом и телесным. Это раскрывает совершенно новые горизонты жизни для определенной части населения и возможность инвестировать знания в процесс конструирования телесного. Формула «Делай себя самостоятельно» активизирует желание творить личную реальность и настраивает на определенные практики. Знание о теле, которые мы находим в древних текстах и на которые опирается Йога, еще раз подчеркивают особую миссию Йоги. Она призывает изучать наши основные взгляды на жизнь, выяснять, какие из них являются нефункциональными в данном времени, нацеливает нас на их замену и на поиск наиболее подходящих для современности.

\section{ЛИТЕРАТУРА}

1. Сарасвати, С. С. (2006). Йога-сутра Патанджали Комментарии. Лекции, прочитанные Свами Сатьянандой Сарасвати. Бихарская школа Йоги, Мунгер, Бихар, Индия. Минск: Ведантамала https://audioveda.ru/uploads/ store/fd5dcd9dc1c2724276e367636974f6799db3e99781384a85c2ff7d7043d2.pdf

2. Йога-сутра Патанджали. (2001). Словарь. Глава 1, 2, 3, 4. Ред. Надежды Богдановой. Пер. с санскр. Свами Вивекананды. Практика и теория йоги. Yoga: Practice and Theory (English). http://www.naturadei.narod.ru/yogasutra.htm\#m33 
3. Лысенко, В. (2009). «Натурфилософия тела» в Индии: аюрведа, санкхья и вайшешикаю Телесность как эпистемологический феномен. (Рос. акад. наук, Ин-т философии; Отв. ред. И.А. Бескова). Москва: ИФРАН, 103-123, https://iphras.ru/uplfile/root/biblio/2009/Telesnost.pdf

4. Патанджали, М. (1998). Йога сутра. Четыре варианта перевода текста. URL: http://lib.ru/URIKOVA/SANTEM/ sutra.txt

5. Философия Йога. (1992). Лекции, читанные в Нью-Йорке зимою 1895- 6 гг. Суоми Вивекананда о РаджаЙоге, или подчинении внутренней природы, и Афоризмы Патаджали с комментариями. Пер. Я.К. Попова. Сарасвати. Вестник Общества Вивекананды. Вып. 1. Москва: Наука, «Восточная литература», 36-162.

6. Элиаде, М. (1994). Священное и мирское. Пер. Н. К. Гарбовского. Москва: МГУ. 144 с.

7. Broad, W. J. (2012). How yoga can wreck your body. The New York Times. 5 January 2012. Available. URL: http:// news.bbc.co.uk/1/hi/7844691.stm .

8. Cherkin, D. C., Sherman, K. J., Balderson, B. H., Cook, A. J., Anderson, M. L., Hawkes, R. J., ... \& Turner, J. A. (2016). Effect of mindfulness-based stress reduction vs cognitive behavioral therapy or usual care on back pain and functional limitations in adults with chronic low back pain: a randomized clinical trial. Jama, 315(12), 1240-1249. doi:10.1001/jama.2016.2323.

9. Dolska, O., Gorodiskaya, O., Tararoyev, J. (2019). Anthropological dimension of constructivism in the culture of Presence, Studia Warmińskie. 56, 105-121. https://czasopisma.uwm.edu.pl/index.php/sw/issue/view/331

10. Lobas, V. (2020). Sociocultural challenges as determinants of the receptions and practices of modern yoga, Cxid, 1(165), 67-74. URL: http://skhid.kubg.edu.ua/issue/view/11969

11. Mooney, J. (1896). The Ghost-Dance religion and the Sioux Outbreak of 1890. Annual Report of the Bureau of American Entology. XIV, 2, Washington, 64-1136.

12. Santorelli, S. F., Meleo-Meyer, F., Koerbel, L., Kabat-Zinn, J. (2017). Mindfulness-Based Stress Reduction (MBSR). Authorized Curriculum Guide. Version Revised and Editedby. https://www.umassmed.edu/globalassets/center-formindfulness/documents/mbsr-curriculum-guide-2017.pdf

\title{
Body Practice Management: from Tradition to Modern (on the example of yoga practices)
}

\author{
Victoria Lobas \\ National Technical University "Kharkov Polytechnic Institute" Kharkov, Ukraine
}

\begin{abstract}
Research object. The modern culture of the West was formed under the pressure of metaphysical discourse with its ontological and epistemological tensions, relying on a rigidly acting subject of a constitutional nature with its characteristic opposition - "spiritual-bodily". The author tries, through a thorough study of the structure of the body, its functional significance, to show the ability to control it and even design it. Yoga practices allow you to look at the human body in a new way. They also contribute to the creation of a special cognitive situation around the topic of body and bodily control. This opens up completely new horizons of life for a certain part of the population and the opportunity to invest knowledge in the process of constructing the corporeal. The formula "Do yourself by yourself" activates the desire to create personal reality and adjusts to certain management practices - anthropotechnics. The article confirms the idea of the integrity of the spiritual and bodily, which Yoga has never lost.

The problem is the study is what knowledge about the body underlines the special mission of Yoga to help maintain a special understanding of bodily control, in particular, as a stepping stone to spiritual growth and how it changes in the context of tradition and modernity.

Purpose of the study: on the basis of the analysis of the bodily practices of Yoga, presented in the ancient texts of Yoga, to come to an understanding of the body as a constructivist practice, and to regard its management as a step towards the spiritual growth of a person.
\end{abstract}


Research methods. Scientific literature analysis, synthesis, generalization. Scientific literature and theoretical interpretation in order to summarize the research carried out on this topic. The analysis of the control of the body and bodily practices was carried out. Its ontological and anthropological dimensions will contribute to the understanding that the body can be an instrument of a person-yoga on the path of ascent to the spiritual, and the phenomenological and epistemological dimensions will emphasize the constructivist nature of the action with it.

Outcomes and conclusions. According to ancient texts, a person's thoughts were based on the starting point - the human individual, from his psychosomatic system. The practice of Yoga introduced the element of bodily control into the culture of the West as a component of spiritual, social and physical life; it became one of the many responses to the challenges of the crisis of the culture of the West. Awareness of such dimensions of the body as sotereological, ontological, epistemological and phenomenological contribute to the creation of a special cognitive situation around the topic of body and bodily control. This opens up completely new horizons of life for a certain part of the population and the opportunity to invest knowledge in the process of constructing the corporeal. The "Do It Yourself" formula activates the desire to create personal reality and tune in to certain practices. The knowledge of the body, which we find in ancient texts and on which Yoga is based, once again emphasize the special mission of Yoga. It encourages us to study our basic outlook on life, to find out which of them are nonfunctional in a given time, aims us at replacing them and at finding the most suitable ones for our time.

Key words: Yoga, bodily practices, construction of the bodily, the body as a construct.

Gautas 20200820

Priimtas 20210430 